\title{
Notas sobre a construção de um discurso historiográfico jurídico
}

\author{
Ricardo Marcelo Fonseca*
}

Sumário: Introdução; 1.Rejeição aos discursos homogêneos e fatalistas; 2.Cuidados específicos em relação ao passado jurídico; 3.Conclusões.

\section{Introdução}

Este estudo parte de uma constatação ao mesmo tempo corriqueira e surpreendente: o jurista, de um modo geral, despreza a importância do conhecimento histórico da instância jurídica. É possível chegar a esta conclusão, dentre outros motivos, ao se constatar a quantidade pequena de obras escritas, publicadas e disponíveis sobre a matéria (em especial obras brasileiras), bem como pelo (des)prestígio desta disciplina dentro de grande parte das grades curriculares das instituições de nosso ensino jurídico (dada sua virtual inexistência, salvo honrosas exceções).

Nos tempos em que a reflexão sobre o direito almeja reagir ao atavismo tradicional que costumava encastelar o âmbito jurídico dentro de paredes rigidamente formais e isolá-lo em relação às demais ciências humanas, é importante, senão crucial, resgatarmos a importância do conhecimento da historicidade do direito, do seu evolver histórico. Trazer à baila a dinâmica histórica do direito implica em tentar compreender uma dimensão até agora pouco explorada pelos juristas (mesmo por alguns daqueles mais atentos à necessidade da interdisciplinariedade). E esta dimensão, disto certamente ninguém duvida, é essencial para que se possa alcançar uma compreensão dos fenômenos jurídicos do passado (e, por conseqüência, também os fenômenos que nos defrontamos no presente), ao mesmo tempo que pode nos apontar respostas (até agora não percebidas) ao problema do esgotamento da juridicidade estatal vivenciada hoje.

* Bacharel e licenciado em História. Advogado. Procurador do INSS. Mestrado na UFPR.

R. Fac. Direito, Curitiba, a.28, n.28, 1994/95, p.249-259 
E resgatar a historicidade do direito implica, antes de mais nada, em colocar o problema de como se irá proceder este resgate. Significa, pois, colocar o problema do método historiográfico jurídico, das formas de se abordar o passado do direito. Esta reflexão pretende ser, assim, um início de discussão sobre alguns elementos metodológicos para a investigação histórico-jurídica. A intenção é apenas a de levantar questões sobre a adequação (e a inadequação) de determinadas posturas teóricas que comumente são assumidas quando se enfrenta o objeto histórico (em especial o objeto histórico jurídico), ensaiando alguns apontamentos - muito provisórios - que possam sugerir respostas aos problemas aqui colocados.

\section{Rejeição aos discursos homogêneos e fatalistas}

Refletir sobre o passado do direito, a meu ver, impõe que se recuse alguns veios de análise que não dão conta, do ponto de vista metodológico, de explicar a realidade histórico jurídica que se busca defrontar. Quero me referir aqui a dois modelos de explicação histórica que, embora ideologicamente contrapostos, são igualmente restritos e insuficientes: 1) o positivismo e 2) uma certa interpretação do marxismo que dominou a segunda internacional e que ficou sendo conhecida por "marxismo leninismo".

A explicação histórica positivista - muito prestigiada, aliás, nas usuais "introduções históricas" que iniciam os manuais jurídicos utilizados nas disciplinas dogmáticas - privilegia os eventos e os fatos como matéria prima do conhecimento. Esta análise busca preencher um tempo vazio e homogêneo com dados, formulando uma história eterna e linear. É o procedimento típico daqueles que empreendem a história do tipo "universal", onde são adicionados dados e mais dados - escolhidos para preencherem este vazio do tempo com suposta neutralidade axiológica - que se encaixam de forma a resultar num discurso encadeado, lógico e concatenado, onde a noção de progresso está pressuposta a cada momento.

Baseados no pressuposto epistemológicen de que podem observar seu objeto de modo tão neutro quanto o fazem os cientistas naturais, os historiadores positivistas acabam produzindo um conhecimento ideologizado, contaminado desde a "escolha" dos dados para preencher seu discurso até o encadeamento que é dado a estes dados, a fim de produzir, no final, um discurso lógico e harmônico. 
Ora, o discurso histórico simplesmente não pode invocar esta linearidade e harmonia porque a realidade histórica com que os sujeitos se defrontam é, ela mesma, complexa e conflitiva. A elaboração de um discurso assim concebido não passa de uma projeção sobre o passado de categorias do presente, o que faz do devir histórico um processo (escatológico) de preparação da atualidade. ${ }^{1}$ A homogeneidade torna possível o apagamento das diferenças, fazendo com que as práticas históricas e papéis sócio-políticos diferentes apareçam como cena tida como una e única. A temporalidade linear, progressiva e contínua é despojada de alternativas históricas reais, ensejando, por conseqüência, um saber necessariamente comprometido com os dominantes, que é sempre um saber que exclui as contingências históricas derrotadas, bem como os saberes alternativos. O saber dominante constitui de modo linear diversidade de projetos, deixando enterradas as diferenças históricas, os esboços do possível. ${ }^{2} \mathrm{O}$ método positivista, é, em suma, o que Walter Benjamin chamava, com muita propriedade, método da empatia, a empatia com o vencedor. Como nos lembra o pensador alemão,

os que num momento dado dominam são os herdeiros dos que venceram antes. A empatia com o vencedor beneficia sempre, portanto, esses dominadores (...) Todos os que até hoje venceram participam do cortejo triunfal, em que os dominadores de hoje espezinham os corpos dos que estão prostrados no chão. ${ }^{3}$

E o produto cultural resultante deste método caraterizado pela empatia com o vencedor somente pode ser vislumbrado com horror, já que, nesta perspectiva, todo monumento de cultura é também um monumento de barbárie. E como a cultura não é isenta de barbárie, tampouco o é o processo de transmissão da cultura. ${ }^{4}$

A história positivista do direito, em suma, amontoa uma série de dados (produtos culturais) do passado, pinçados por escolhas nunca confes-

1 Antonio Manuel Hespanha, Justiça e litigiosidade história e prospectiva, Lisboa, Fundação Calouste Gulbenkian, 1993, p. 51.

2 Marilena Chaú, Prefácio "in Edgard De Decca, (O) silêncio dos vencidos, $4^{\text {a }}$ ed., São Paulo, brasiliense, 1988, p. 15.

3 Walter Benjamin, Obras escolhidas, magia e técnica, arte e política, $3^{a}$ ed.. São Paulo, brasiliense, 1987, p. 225.

4 Walter Benjamin, Obras..., op. cit., p. 225.

R. Fac. Direito, Curitiba, a.28, n.28, 1994/95, p.249-259 
sadas, forjando um discurso histórico linear (porque é excludente) e excludente (porque é linear), relegando ao esquecimento as alternativas históricas dos vencidos, daqueles que em determinado momento foram (e talvez continuem sendo) dominados.

O resultado é um conhecimento que poucas questões tem a oferecer para o jurista preocupado com a reflexão acerca do direito atual. Um amontoado de dados que desembocam de um modo lógico - como se esta fosse a via inexorável do processo histórico! - no presente (geralmente pela via das causas e conseqüências) apenas conforta aqueles que acreditam no progresso da sociedade.

Se a historiografia positivista deve ser recusada em vista de ser insuficiente do ponto de vista metodológico e por estar atrelada a uma concepção de mundo que se pode classificar, em última análise, como conservadora, devemos também, por outro lado, recusar aquele veio que, partindo de uma perspectiva revolucionária de mundo, coloca a classe trabalhadora como demiurgo da história e como encarregado da missão (inevitável e inexorável) de transformação revolucionária da sociedade.

Quero me referir às concepções ligadas ao chamado "marxismo-leninismo", outrora orientadas pela batuta de Stalin, que insistiam em ver o processo histórico como um caminho inexorável, onde se sucediam diversos modos de produção na medida em que o desenvolvimento das forças produtivas iam se chocando com as relações de produção (do escravista para o feudal, do feudal para o capitalista e do capitalista para o comunista). Para esta concepção, as diretrizes econômicas fariam com que qualquer formação social evoluísse nos moldes em que Marx explicou o surgimento do capitalismo ocidental (vide a obra de Werneck Sodré, ${ }^{5}$ que pressupõe a existência do regime escravista e feudal no Brasil!), fazendo com que o regime comunista adviesse de modo natural, como que bastando aos sujeitos históricos esperarem sentados o advento de uma nova sociedade onde não haveria apropriação privada dos meios de produção...

Tal concepção de história acabava, evidentemente, por se caracterizar por um mecanicismo inconcebível e um determinismo inaceitável. Pretender que as formações sociais sigam sempre um caminho pré-determi-

5 Nelson Werneck Sodré, História da burguesıa brasileira, Petrópolis, Vozes, 1983. 
nado e acreditar que este caminho terá um fim inexorável, significa desprezar todas as variantes históricas que podem atuar numa determinada realidade. Significa também excluir o sujeito da história, já que ele não passará de um elemento insignificante e passivo no processo irreversível de transformação da sociedade. Toda a potencialidade de atuação política do sujeito é substituída por uma força messiânica que se situa acima dos homens, que podem esperar, atavicamente, o advento das mudanças anunciadas pelo profeta. Ademais, o caráter determinante da "infra-estrutura" (a economia) sobre as demais instâncias "super-estruturais", que tanta importância teve na superação da sociedade feudal para a capitalista - como nos demonstrou Marx, acabam tendo, para esta corrente, uma validade universal incompatível para formações históricas não ocidentais e para formações históricas antigas.

É de ressaltar também que esta opção marxista de análise geralmente vislumbra o direito de um modo deveras unilateral, reduzindo-o a uma mera expressão de domínio de classe, mero serviçal da burguesia no seu intento de dominação. Exemplo teórico desta abordagem pode ser encontrada na experiência inicial soviética na reflexão do direito, que se ressentia de certa unilateralidade de análise, descambando ou num economicismo reducionista, ou num voluntarismo simplificador. ${ }^{6}$

O historiador do direito, neste campo, perceberá limitações intransponíveis à explicação das sociedades passadas, e principalmente na compreensão de suas formações jurídicas - reduzidas a mero apêndice de uma estrutura de classe. A meta final de destruição do Estado-dominador tão cara à idéia "marxista leninista" de encarar a revolução - implica também, para esta corrente, na destruição de todas as formas jurídicas, que não passam de instrumento formal de que dispõe o Estado para assegurar esta dominação. E a tarefa do historiador do direito seria realmente inglória se se reduzisse, apenas, a relatar a trajetória que culminaria com as exéquias da instância jurídica...

6 Clèmerson M. Clève, "Uso alternativo do direito e saber jurídico", in Lições de direito alternativo, coord. de Edmundo Arruda Jr., São Paulo, acadêmica, 1991, p. 103/105.

R. Fac. Direito, Curitiba, a.28, n.28, 1994/95, p.249-259 


\section{Cuidados específicos em relação ao passado jurídico}

A tarefa de reconstituição histórica da experiência jurídica deve, ainda, tomar algumas precauções teóricas para afastar a tendência de isolar o objeto de estudo ou de rejeitar os recursos interdisciplinares que devem socorrer a análise do jurista.

É que o estudo da história de uma instituição determinada, como é o direito, pode sofrer o vício de valorizar de um modo desmedido a própria instituição em questão em detrimento de todas as outras ingerências históricas que com ela se defrontam. Em outras palavras, existe um perigo de abandonar a perspectiva da totalidade no estudo, descurando-se da compreensão do direito como espaço ligado a um todo. composto também pelas esferas sociais, políticas, culturais, religiosas, etc., de cada época determinada. Tal procedimento enseja uma perspectiva unilateral, que sofre o perigo de desprezar elementos importantes na explicação da formação e da evolução do jurídico.

Em suma, importa adotar uma perspectiva que repudie a explicação "do direito pelo direito", numa pretensiosa auto-suficiência que não encontra eco na realidade histórica estudada. Não se pode prescindir de um profundo mergulho no estudo das instituições políticas, sociais, econômicas, religiosas, mentais, etc.. na busca de uma compreensão cada vez mais totalizante do jurídico, evitando isolar o direito do processo histórico real em que ele está inserido.

O direito deve ser analisado, também, dentro de sua própria dinâmica histórica, captado no seu próprio processo de constituição histórica, em seu "fazer-se", respeitando-se toda a gama de injunções que ele se defrontou. Devem ser obedecidas as conjunturas específicas de cada passo do processo de constituição histórica do direito, com suas diversas inter relações com as outras esferas atuantes num dado momento, respeitando-se os elementos que compõe o quadro no qual o direito está então moldado. Evita-se desta forma o discurso linear. harmônico e coerente que caracteriza a perspectiva positivista, já que busca-se tendencialmente captar o objeto histórico de estudo em sua própria dinâmica, e não como uma etapa necessária e lógica que resultou no presente.

Estudar, por exemplo, a recepção das tradições do direito romano na constituição do direito ocidental desviando-se deste horizonte (vale dizer: 
tomando como postura o desprezo à multiplicidade de injunções históricas que atuaram nesta assimilação e sem considerar a complexidade do processo que afetou as instituições jurídicas, por uma dialética de exclusões e inclusões), implica em ignorar toda a riqueza do fenômeno histórico e faz com que se dilua a tessitura da realidade em que nosso direito se forjou. com o periga de relegar do conhecimento elementos importantes para a compreensão histórica.

Deve-se também ter em conta que o direito é uma esfera que ao mesmo tempo determina e é determinada pelo campo social, político, econômico, etc., atuantes num dado momento, por meio de um processo dialético, diacrônico e não linear de implicações. Esta é uma postura que implica em repudiar toda forma de determinismo histórico (porque todo determinismo reduz de modo esquemático a complexidade do real). Não se pode conceber que o direito tenha, só ele, o condão de determinar instituições políticas, bem como. "mutatis mutandi", o direito não é determinado passivamente por esta esfera. Tampouco o direito pode ser visto como mero reflexo das estruturas econômicas ou de produção de uma determinada sociedade. ou vice-versa.

Quer se enfatizar que o objeto histórico do direito, embora não possa ser analisado sem que seja inserido na complexidade de toda a conjuntura histórica, como acima colocado, também não deve ser diluído neste processo, como se não tivesse nenhuma especificidade própria. $\mathrm{O}$ direito guarda uma dinâmica particular, que embora esteja entrelaçada com as demais ingerências que o acompanham no processo histórico (o social. o político. o econômico), mantém sua peculiaridade, que também é capaz de ser determinante daquelas esferas. É, assim, uma instituição com uma autonomia relativa, com especificidade e dinâmica próprias e que possui uma historicidade que lhe é inerente, já que existem estruturas histórico jurídicas típicas e com seus próprios determinantes.

Toda a formação da dogmática moderna, por exemplo, que encontra raízes na própria Idade Média, que molda-se na época da formação dos Estados Nacionais Modernøs e que adquire contornos específicos na contemporaneidade, somente pode ser explicada numa perspectiva histórico jurídica. Infrutífero será tentarmos compreender a formação da dogmática somente pelo rigor das normas religiosas que impregnaram o direito medieval ou pela sistematização jurídica que foi exigida no processo de unificação política dos Estados Modernos. As explicações pelo religioso ou pelo

R. Fac. Direito. Curitiba, a.28,n.28. 1994/95, p. 249-259 
político, aqui, não passarão de úm reducionismo simplista, onde estará perdida toda a perspectiva histórica da formação da dogmática. Não poderão ser compreendidos o seu peso e seu significado para o direito atual, exatamente pelo reducionismo teórico em que incorrem estes tipos de análise ao não perceberem a autonomia relativa do direito enquanto objeto de estudo e da história do direito enquanto disciplina autônoma.

Como corolário da postura teórica de compreender o direito como algo imbricado à complexidade da tessitura histórica na qual ele se molda, existe uma outra postura, que não se deve descurar: a de encarar o direito como produção humana, como algo forjado pelo homem em seu processo de constituição histórica. O alçapão teórico de vislumbrar o direito como algo hipostasiado, ${ }^{7}$ como algo apartado da experiência histórica, importa em vislumbrar o evento com que se defronta com estranhamento, como algo externo. Como conseqüência, perde-se a noção de sua historicidade, não se lhe compreende em seu processo de constituição e, como decorrência, não se vislumbra o objeto do direito como algo que possa ser modificado pela ação humana.

Analisar o direito como objeto histórico, implica, assim, em concebê-lo como produção humana, como algo encarnado em projetos, conscientes ou não, de grupos ou classes sociais. Implica em vislumbrá-lo como algo referencial ao homem e como sua produção, pois a idéia de direito somente adquire sentido quando encarnado em pessoas e situações humanas.

Voltando ao exemplo da recepção da tradição romanística no direito ocidental, pode-se dizer que pecam por literalmente excluir o homem da história aquelas análises que vislumbram esta tradição como ente externo que se "amolda" naturalmente à tessitura jurídica de uma determinada época, como se as experiências, relações e instituições humanas simplesmente se adaptassem, atávica e passivamente, a esta tradição. É como se as experiências histórico jurídicas de nossos antepassados fossem completamente alheias a qualquer ato de vontade, sendo modeladas e invadidas por entes externos em todos os seus flancos.

7 Luis Fernando Coelho, Teoria critica do direito, $2^{\mathrm{a}}$ ed., Porto Alegre, Sergio Fabris, 1991, p. 25 e segs. 


\section{Conclusões}

Conclui-se, pois, que a realidade histórica do direito não é unívoca e harmônica, passível de ser reduzida a um papel político ou econômico numa dada formação social (seja o papel de regulador técnico de conflitos ou seja o papel de dominador e opressor). É um campo conflitivo, um espaço de lutas, onde a criação de direitos e expansão de liberdades sofrem fluxos e refluxos, avanços e recuos.

Assim, deve-se analisar a instância jurídica como um espaço complexo numa dada formação histórica, onde coabitam (de modo conflitivo e paradoxal) forças que instituem formas de dominação (e representações ideológicas para legitimar esta dominação) e forças que limitam e restringem esta mesma dominação. Podem até estar presentes em uma dada instância jurídica os gérmens de uma mudança institucional na sociedade, com as sementes da superação desta dominação.

A reconstituição histórica do direito tem que se desviar da empatia com um discurso dominante, com o saber lógico comprometido com a lógica da exclusão, da empatia, enfim, com um monumento cultural que não passa de um monumento de barbárie. Deve também se esquivar dos etapismos e mecanicismos que reduzem a riqueza do real a esquemas explicativos providencialistas. Deve vislumbrar as alternativas históricas reais, com seus sujeitos e situações reais, ouvindo seus apelos, ainda que estes não tenham sido ouvidos pelos seus contemporâneos. Deve se comprometer a escovar a história a contrapelo. ${ }^{8}$

É que a postura de afastamento com um discurso linear e simplificado pressupõe perceber o passado histórico-jurídico como monumento a ser reconstituído, para ser captado em seus "relâmpagos fugazes" em que o passado se revela. Significa captar as reminiscências, tal como elas relampejam no momento de perigo (pois o passado só é recuperado quando é visado pelo presente), a fim de despertar no passado as centelhas da esperança, as alternativas históricas. ${ }^{9}$ A tarefa do historiador do direito é, pois, proceder às perguntas adequadas ao passado jurídico a fim de que este se revele, para que este seja apropriado pelo presente. E não se pode perder

8 Walter Benjamin, Obras..., op. cit., p.225.

$9 \quad$ Walter Benjamin, Obras..., op. cit., p.224.

R. Fac. Direito, Curitiba, a.28, n.28, 1994/95, p.249-259 
de vista que quase que todo o "acontecer" histórico do direito está por ser resgatado, já que a herança cultural da experiência jurídica que nos foi transmitida é apenas uma faceta (minoritária) da experiência vivenciada (basta lembrar o caráter marginal do direito escrito e estatal até a Europa moderna ${ }^{10}$ ).

Trata-se, enfim, de buscar na reconstituição histórica do passado tão neglicenciado pelo jurista no seu trabalho de compreensão do direito atual - a recuperação de expectativas históricas vencidas, dos becos sem saída, dos apelos que foram sufocados. E quanto mais adequadas forem as perguntas formuladas a este passado, maior a possibilidade de obtermos respostas aos impasses do direito atual, na medida da redenção deste passado perdido, já que, como nos lembram as belas palavras de Walter Benjamim,

"O passado traz consigo um índice misterioso, que o impele à redenção. Pois não somos tocados por um sopro do ar que foi respirado antes? Não existiram, nas vozes que escutamos, ecos de vozes que emudeceram? Não têm as mulheres que cortejamos irmãs que elas não chegaram a conhecer? Se assim é, existe um encontro secreto marcado entre as gerações precedentes e a nossa. Alguém na terra está à nossa espera. Neste caso, como a cada geração, foi-nos concedida uma frágil força messiânica para a qual o passado dirige um apelo. Esse apelo não pode ser rejeitado impunemente". ${ }^{11}$

\section{Referências Bibliográficas}

ARRUDA JR., Edmundo Lima de (org.). Lições de direito alternativo. São Paulo: Acadêmica, 1991.

BENJAMIN, Walter. Obras escolhidas. magia e técnica, arte e politica. $3^{\text {a }}$ ed. São Paulo: Brasiliense, 1987.

COELHO, Luis Fernando. Teoria critica do direito. $2^{\mathrm{a}}$ ed. Porto Alegre: Sergio Fabris, 1991.

DE DECCA, Edgard. O silêncio dos vencidos. $4^{\mathrm{a}}$ ed. São Paulo: Brasiliense, 1988.

10 Antonio Carlos Wolkmer, Pluralismo jurídico, fundamentos de uma nova cultura do direito, São Paulo, alfa ômega, 1994, p. 168 e ss. e Antonio Manuel Hespanha, Justiça.... op. cit., p. 15.

11 Walter Benjamin, Obras... op. cit., p. 223. 
HESPANHA. Antonio Manuel. Justiça e litigiosidade: história e prospectiva. Lisboa: Fundação Calouste Gulbenkian, 1993.

WOLKMER, Antonio Carlos. Pluralismo juridico: fundamentos de uma nova cultura do direito. São Paulo: Alfa Ômega, 1994.

R. Fac. Direito, Curitiba, a.28, n.28, 1994/95, p. 249-259 